\title{
Urethral Stick Dosage Form
}

National Cancer Institute

\section{Source}

National Cancer Institute. Urethral Stick Dosage Form. NCI Thesaurus. Code C150006.

Solid sterile single-dose preparation, usually rod-shaped and of a size adapted to the dimensions of the urethra, intended for insertion into the urethra. They may be prepared by compression or molding. 